\title{
Left heart bypass in the surgery of aortic coarctation in children
}

\author{
N J BUCKELS, R G WILLETTS, K D ROBERTS
}

From Birmingham Children's Hospital, Birmingham

ABSTRACT Of 47 children over the age of 1 year who underwent repair of aortic coarctation during 1978-85, 22 had the operation performed with left heart bypass because the distal aortic pressure was below $50 \mathrm{~mm} \mathrm{Hg}$ after the initial application of the arterial clamps. One further child had an elective left heart bypass. Satisfactory distal perfusion was achieved in all 23 patients. There were no deaths related to the use of left heart bypass but three complications occurred. One child had a mild transient hemiparesis on the ninth postoperative day and two had a pericardial effusion.

\section{Introduction}

Spinal cord injury is a major complication of surgery on the descending thoracic aorta. Three children undergoing surgery for coarctation at the Birmingham Children's Hospital before the use of left heart bypass suffered spinal cord injuries, two remaining paraplegic and one making an almost complete recovery. ${ }^{1}$ Previous work suggested that after clamping of the aorta a mean distal aortic perfusion pressure of less than $50 \mathrm{~mm} \mathrm{Hg}$ may predispose to spinal cord injury. ${ }^{2}$ We therefore adopted the use of left heart bypass in children whose mean distal aortic pressure was less than $50 \mathrm{~mm} \mathrm{Hg}$ when the aortic clamps were applied in an effort to avoid these and other reported complications. ${ }^{23}$ There were no other alterations in our surgical technique or anaesthetic management to increase the distal perfusion pressure. We report the use of partial left heart bypass in 23 children undergoing surgery of the thoracic aorta by one surgeon at the Birmingham Children's Hospital.

\section{Patients and methods}

\section{PATIENTS}

From 1978 to 1985 surgery for coarctation of the aorta was carried out on 110 patients - 63 infants and 47 children over 1 year of age. Of the 47 children, 22 had a mean distal perfusion pressure on trial cross clamping of below $50 \mathrm{~mm} \mathrm{Hg}$ (range $25-48$, mean $36 \mathrm{~mm} \mathrm{Hg}$ ) and therefore had left heart bypass performed. Thirteen children underwent a primary repair for coarctaAddress for reprint requests: Mr N J Buckels, Cardiothoracic Surgery
Unit, Royal Victoria Hospital, Belfast BT12 6BA.

Accepted 26 September 1988 tion (eight boys, five girls; mean age 7 years) and nine had a reoperation for recurrent coarctation (six boys, three girls; mean age 9 years). One child, with an aneurysm at the site of a coarctation previously repaired with pericardium at the age of 12 days, had an elective left heart bypass.

\section{OPERATIVE TECHNIQUE}

All patients had continuous intraoperative monitoring of arterial blood pressure in the right radial artery and in either a femoral artery or the thoracic aorta. A posterolateral thoracotomy was performed and the pleura over the mediastinum incised to display the coarctation. The aorta was mobilised above and below the coarctation to allow the application of arterial clamps. If after application of the cross clamps to the left subclavian artery and the aorta above and below the operation site the distal perfusion fell below $50 \mathrm{~mm} \mathrm{Hg}$, the clamps were removed while the bypass equipment was assembled and primed. The patient was given $3 \mathrm{mg} / \mathrm{kg}$ heparin for anticoagulation. A pursestring suture was inserted into the descending aorta (femoral artery in the first six patients), the pericardium opened, and a second pursestring suture inserted into the left atrial appendage. After division of the bypass loop the arterial cannula was inserted. The left atrial cannula was then inserted, with positive pressure kept on the lungs to prevent the introduction of air into the left side of the heart. The patient was put on partial bypass at a flow calculated to be half the normal resting cardiac output of $2.61 / \mathrm{m}^{2}$ a minute. Oxygenated blood from the left atrium was drained to a reservoir and returned under pressure via a roller pump into the distal thoracic aorta or femoral artery (figure). After completion of the repair the distal aortic clamp was removed first and if haemostasis was 


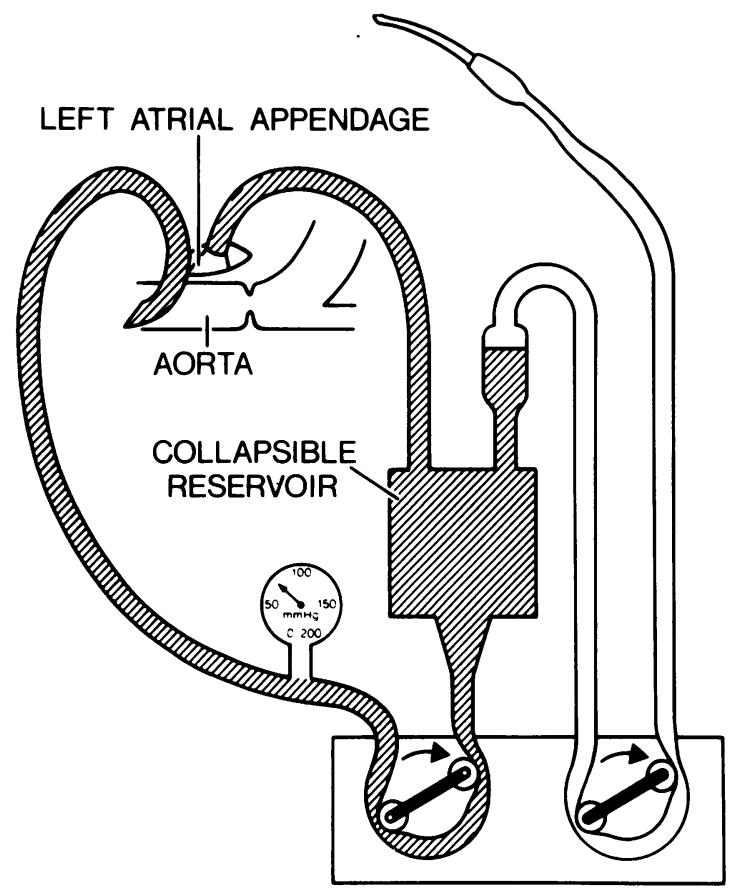

Circuit diagram for left heart bypass in the surgery of coarctation.

adequate the proximal aortic and subclavian clamps were removed. Bypass was then discontinued and the cannulas were removed, care again being taken not to introduce air into the left atrium. The heparin was reversed with protamine sulphate as calculated by Hepcon. The perfusionist had no difficulty in maintaining distal pressure (range $55-85 \mathrm{~mm} \mathrm{Hg}$, mean $68 \mathrm{~mm} \mathrm{Hg}$ ) and balancing the proximal blood pressure during heart bypass.

Eighteen of the repairs were carried out with preclotted Dacron patches and two with Dacron straight grafts. Two resections were performed with end to end anastomoses. The child with an aneurysm at the site of his previous coarctation had a Microvel straight graft.

\section{Results}

The mean age of the 23 children was 7 years 8 months (range $2-15$ years). There were 15 boys and eight girls. Two of the girls had Turner's syndrome. Only two of the chidren had rib notching on the chest radiograph.

The total bypass time ranged from 18 to 79 minutes with a mean of 35 minutes. Haemorrhage during surgery was a problem in one child who was hypertensive before operation. He bled from his left subclavian artery at the insertion of the patch because the artery split; this was eventually dealt with by doubly ligating the artery at this point and there were no postoperative problems. Postoperatively the volumes aspirated by chest drain ranged from 60 to 455 (mean 186) $\mathrm{ml}$.

There was one neurological complication. A 5 year흠 old girl was readmitted on the ninth postoperative day? with a mild left hemiparesis, which fully resolved@ spontaneously; she may have had a small emboluses related to her left atriotomy. A 15 year old girl had $a$ pericardial effusion $(150 \mathrm{ml})$ drained postoperatively.The boy with the aneurysm also developed a small $\vec{\omega}$ pericardial effusion, which resolved spontaneously.

Postoperative hypertension occurred in seven chil- $\vec{x}$ dren and was treated briefly with labetolol. Four $\vec{\omega}$ children required longer term treatment with atenolol $\vec{N}$ or propranolol; in three of these treatment was ${ }_{-}^{*}$ stopped after six weeks but the fourth child was referred to a different centre for treatment of renal ${ }^{\omega}$ artery stenosis.

Since 1985 a further 15 left heart bypasses, 14 for coarctation and one for an interrupted aortic arch, $\mathbb{\infty}$

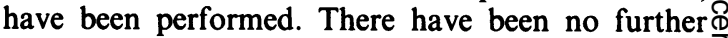
neurological injuries and no major complications.

\section{Discussion}

The mechanism of cord injury in repair of coarctatio̊ำ is not proved. Recent work has shown that in the pig, which is similar to man in its spinal cord blood supp doubly cross clamping the thoracic aorta produced steal syndrome from the spinal artery, blood flowing $\mathbb{Q}$ to the lower body down the spinal artery at the expense $\overrightarrow{\vec{\rho}}$ of the spinal cord. ${ }^{4}$

Surgery on the thoracic aorta without spinal cord $\frac{3}{5}$ protection for traumatic rupture of the aorta or thoracic aneurysm is associated with cord ischaemia in up to $24 \%$ of patients. ${ }^{3}$ The child with coarctation, however, usually develops a good collateral circula- $\frac{\tilde{D}}{x}$ tion. This acts as a protective mechanism at the time of $\frac{0}{-}$ surgery in most but not all of these children. Because of this the incidence of cord damage in surgery for $\delta$ aortic coarctation is in the region of $0.3-1.5 \% .^{5-7}$ It is rare, although it has been reported, below the age of 1 응 year. ${ }^{89}$ In later childhood it is more common, with a maximal incidence of $4 \%$ in the $11-16$ age group. ${ }^{7}$ It has been reported after only 15 minutes' aortic occlusion, 9 so that even with the quickest anastomotic . techniques the patient may be at risk. Many series $N$ report a mean cross clamp time longer than this. ${ }^{6710} \mathrm{~N}$ There is no evidence that the number of intercostal 0 vessels ligated affects the incidence of paraplegia, perhaps because the flow in these vessels is reversed in $\frac{}{D}$ coarctation. ${ }^{611}$ Most authors believe that paraplegia is $\stackrel{?}{-}$ caused by ischaemic damage to the cord secondary to 0 poor distal perfusion during the period of aortic ${ }_{0}^{\circ}$ occlusion at the time of surgery. Hyperthermia is a $\stackrel{\mathbb{D}}{\circ}$ possible exacerbating factor, cord ischaemia becom- $\mathbb{\mathbb { D }}$ 
ing critical owing to the higher metabolic rate and oxygen requirement of neural tissue with low perfusion. ${ }^{8}$ Distal perfusion pressure is usually lower when it is also necessary to clamp the left subclavian artery."

The use of shunts, left heart bypass, and hypothermia have been shown to protect the spinal cord during other types of surgery on the descending aorta. The use of vasoconstricting drugs (metaraminol) has also been suggested. ${ }^{11}$ Because the incidence of spinal cord injury is low the benefit of these techniques during surgery of aortic coarctation is still not proved. They should be used only if they can be shown to add little or no risk.

The serial recording of somatosensory evoked potentials is reported to be a relatively accurate predictor of spinal cord damage, showing early changes in spinal cord function at a stage when the damage is reversible. ${ }^{10-13}$ Its widespread use should help to decrease the incidence of spinal cord damage. Unless, however, the surgeon is prepared to use a technique to increase distal aortic perfusion and by inference spinal cord perfusion, early evidence of damage from evoked potentials will merely encourage the surgeon to complete his anastomosis quickly or become simply a predictor of permanent damage.

Left heart bypass to protect the spinal cord in patients undergoing operations on the thoracic aorta was first described in 1957 by Cooley ${ }^{14}$ and Gerbode. ${ }^{15}$ They reported additional benefits from decompressing the left ventricle and minimising proximal hypertension. Moreover, because the position of the lower cross clamp in patients with coarctation is above $\mathrm{T}$, the level of the usual aortic origin of the artery of Adamkiewitz, the danger of spinal cord injury should be minimised. Anatomical variations of the artery of Adamkiewitz occur, however, and have been proposed as an important additional risk factor in patients undergoing thoracic aortic surgery, ${ }^{6}$ and this technique may not protect against paraplegia if the origin of the artery is excluded by the positioning of the arterial clamps. The use of somatosensory evoked potentials may identify patients with left heart bypass who are at risk so that the cross clamps may be repositioned or the anastomosis fashioned more rapidly. There have been few reports of the use of left heart bypass in children. ${ }^{16}$

The incidence of paraplegia after reoperation is thought to be higher than after primary repair and distal cord protection may be more important in this group ${ }^{616}$ Surgery to the descending thoracic aorta not related to coarctation is rare in children, but in traumatic rupture spinal cord protection should be considered.

Experience at the Birmingham Children's Hospital has shown that left heart bypass is not without morbidity, two episodes of pericardial effusions and one episode of transient mild hemiplegia following left heart bypass in 23 children. In a child with haemorrhage from the subclavian artery, not related to the bypass, it allowed blood to be saved and retransfused, and proximal hypertension at the time of bypass was felt to be less of a problem in these children than in those who did not have bypass.

Morbidity has been reported with other temporary shunting techniques, such as haemorrhage from the left ventricle in transventricular shunts and bleeding from the proximal aortic insertion site in the aortic arch to descending aortic shunts. ${ }^{17}$ These shunts have the advantage of being heparin lined and so not requiring full anticoagulation. Permanent shunting using a prosthetic bypass graft inserted with side biting clamps has been suggested as a technique to avoid prolonged cross clamping of the aorta, though we have no experience of the technique. It would ensure perfusion of the distal aorta throughout surgery and its use would be appropriate if no other technique were available to ensure distal perfusion in a patient found to have a low distal perfusion pressure after trial cross clamping. The long term problem of patency and the possibility that further surgery will be required if the child outgrows the graft together with increased difficulty if reoperation is necessary may limit its potential. Left heart bypass has the advantage of collecting blood from a low pressure system. A smaller distal aortic cannula can be used than with a shunt and any substantial haemorrhage is more easily dealt with because the reservoir is full of blood and a sucker can collect and recirculate any blood lost. During bypass there is a tendency for the core temperature to fall, acting as a further method of cord protection. The advantage over the use of topical hypothermia is that half of our children do not require a shunt, and theatre time can be saved by not cooling and rewarming a child unnecessarily. There also remains the slight risk of ventricular fibrillation at low temperatures.

Keen, in Bristol, reported the responses to a questionnaire sent to surgeons in Great Britain and Ireland, and found that over half now measured distal aortic pressures during surgery to the descending aorta. ${ }^{5} \mathrm{He}$ suggested that in the future a surgeon might be open to litigation if he failed to measure distal perfusion pressure or to monitor spinal cord function by somatosensory evoked potentials and provide distal aortic shunting or bypass for "at risk" patients. We have sympathy with this view and indeed this is our standard practice. All methods of shunting or bypass, however, have their own morbidity and the morbidity and mortality in a shunt-bypass group and an unprotected group have not been compared formally. It must therefore still be left to the individual surgeon to determine his own policy. A large multicentre trial would be required to show benefit when the reported 
incidence of paraplegia is $0 \cdot 3-1 \cdot 5 \%^{5-7}$ and it could still be inconclusive.

\section{References}

1 Puntis JWL, Green SH. Ischaemic spinal cord injury following cardiac surgery. Arch Dis Child 1985;60: 517-20.

2 Hughes RK, Reemtsma K. Correction of coarctation of the aorta: manometric determination of safety during test occlusion. J Thorac Cardiovasc Surg 1971;62:31-4.

3 Katz NM, Blackstone EH, Kirklin JW, Karp RB. Incremental risk factors for spinal cord injury following operation for acute traumatic aortic transection. $J$ Thorac Cardiovasc Surg 1981;81:669-74.

4 Wadouh F, Arndt CF, Artz EO, Borst HG, Wadouh R. The mechanism of spinal cord injury after simple and double aortic cross-clamping. J Thorac Cardiovasc Surg 1986;92:121-7.

5 Keen G. Spinal cord damage and operations for coarctation of the aorta: aetiology, practice, and prospects. Thorax 1987;42:11-8.

6 Brewer LA, Fosburg RG, Mulder GA. Spinal cord complications following surgery for coarctation of the aorta. J Thorac Cardiovasc Surg 1972;64:368-81.

7 Lerberg DB, Hardesty RL, Siewers RD, Zuberbuhler JR, Bahnson HT. Coarctation of the aorta in infants and children: 25 years of experience. Ann Thorac Surg 1982;33:159-70.

8 Crawford FA, Sade RM. Spinal cord injury associated with hyperthermia during aortic coarctation repair. $J$ Thorac Cardiovasc Surg 1984;87:616-8.

9 Pennington DG, Dennis MH, Swartz MT. Repair of aortic coarctation in infants: experience with an intraluminal shunt. Ann Thorac Surg 1985;40:35-40. ज़

10 Kaplan BJ, Friedman WA, Alexander JA, Hampson SR. Somatosensory evoked potential monitoring of spinal cord ischaemia during aortic operations. Neurosurgery 1986;19:82-90.

11 Krieger KH, Spencer FC. Is paraplegia after repair of $\cong$ coarctation of the aorta due principally to distal $\%$ hypotension during aortic cross clamping? Surgery $\overrightarrow{0}$ 1985;97:2-7.

12 Laschinger JC, Cunningham JN, Catinella FP, et al. Detection and prevention of intraoperative spinal cord ischaemia after cross clamping of the thoracic aorta: $\vec{x}$ use of somatosensory evoked potentials. Surgery 1982;92:1109-14.

13 Dasmahapatra HK, Coles JG, Taylor MJ, et al. Iden- $\vec{N}$ tification of risk factors for spinal cord ischaemia by $\vec{A}$ the use of monitoring of somatosensory evoked potentials during coarctation repair. Circulation 1987;76 (suppl III):14-8.

14 Cooley Denton A, de Bakey ME, Morris GJ. Controlled extracorporeal circulation in the surgical treatment of aortic aneurysm. Ann Surg 1957;146:473-86.

15 Gerbode F, Braimbridge M, Osborn JJ, Hood M, French $S$. Traumatic thoracic aneurysms: treatment by resection and grafting with the use of an extracorporeal bypass. Surgery 1957;42:975-85.

16 Beekman RH, Rocchini AP, Behrendt DM, Rosenthal A. $\infty$ Reoperation for coarctation of the aorta. Am J CardiBl 1981;48:1108-14.

17 Frantz PT, Murray GF, Shallal JA, Lucas CL. Clinic and experimental evaluation of left ventriculo-ilias shunt bypass during repair of lesons of the descending thoracic aorta. Ann Thorac Surg 1981;31:551-7. 